\title{
FELICIDADE INTERNA BRUTA E EMISSÃO DE NITROGÊNIO: I- APLICANDO OS PARÂMETROS QUÍMICOS E MATEMÁTICOS
}

\author{
Carolina Franchini ${ }^{1}$
}

\author{
Gilmar de Almeida Gomes²
}

\begin{abstract}
RESUMO
O impacto ambiental deve utilizar indicadores de desenvolvimento de uma nação não só indicadores econômicos como o PIB, já tem dados disponíveis na literatura de outros índices, como o PIB e IDH, que podem significar uma melhor estimativa do impacto ambiental causado pelo desenvolvimento. $O$ IDH e a FIB medem o desenvolvimento de uma nação levando em consideração outros fatores que não são só econômicos. O crescimento populacional e o desenvolvimento econômico, estão gerando preocupações sobre como garantir formas mais sustentáveis de desenvolvimento humano (INTEGRATED MODELLING OF GLOBAL ENVIRONMENTAL CHANGE, 2006). O nitrogênio é um indicador deste impacto, por exemplo, na forma de óxido de dinitrogênio $\left(\mathrm{N}_{2} \mathrm{O}\right)$ é altamente nocivo ao meio ambiente, pois provoca a chuva ácida e a destruição da camada de ozônio, além de contribuir para o aquecimento global, sendo 237 vezes mais impactante que o $\mathrm{CO}_{2}$. Indicadores econômico são usados como referência para estimar como o meio ambiente está sendo impactado (INTEGRATED MODELLING OF GLOBAL ENVIRONMENTAL CHANGE, 2006).O conceito mais amplo para medir o desenvolvimento de uma sociedade é o índice de felicidade interna bruta. Neste trabalho mediu-se a Nem utilizando equações propostas para o PIB e adaptadas para o FIB, percebeu-se que as regiões mais desenvolvidas do mundo são as que mais liberam nitrogênio na atmosfera, enquanto as regiões mais pobres são menos expressivas, dados concordantes com a literatura utilizada.
\end{abstract}

PALAVRAS-CHAVE:Meio ambiente. Emissão de Nitrogênio. Felicidade Interna Bruta.

\section{GROSS NATIONAL HAPPINESS AND NITROGEN EMISSION: I-APPLYING THE CHEMICAL AND MATHEMATICAL PARAMETERS}

\footnotetext{
${ }^{1}$ Acadêmica de Engenharia de Alimentos da Universidade do Estado de Santa Catarina. carol_slo@hotmail.com.

${ }^{2}$ Doutor em Química, Professor da Universidade do Estado de Santa Catarina. gilmargomess@yahoo.com.br.
} 


\section{Periódica Eletrânica \\ Fórum Ambiental}

da Alta Paulista
Volume 11, Número 02, 2015

Campo, Agronegócio

e as Práticas Sustentáveis

\section{ABSTRACT}

The environmental impact should use development indicators of a nation not only economic indicators such as GDP, already has data available in the literature of other indices, such as GNH and HDI, which can mean a better estimate of the environmental impact of development. The HDI and the GNH measure the development of a nation taking into account other factors that are not only economics. Population growth and economic development, are raising concerns about how to ensure more sustainable forms of human development (INTEGRATED MODELLING OF GLOBAL ENVIRONMENTAL CHANGE, 2006). Nitrogen is an indicator of this impact, for example in the form of dinitrogen oxide $\left(\mathrm{N}_{2} \mathrm{O}\right)$ is highly harmful to the environment because it causes acid rain and depletion of the ozone layer and contribute to global warming, with 237 times greater impact than $\mathrm{CO}_{2}$. Economic indicators are used as a reference for how to estimate the environment is being impacted (INTEGRATED MODELLING OF GLOBAL ENVIRONMENTAL CHANGE, 2006). The broader concept to measure the development of a society is the gross national happiness index. In this paper measured the Nem using equations for GDP and adapted to the GNH, it was realized that the more developed regions of the world are the biggest release nitrogen into the atmosphere, while the poorest regions are less significant, consistent data used literature.

KEY-WORDS: Environment.Development Index. Gross National Happiness.

\section{BRUTO NACIONAL EMISIÓN DE NITRÓGENO Y FELICIDAD: APLICAR LOS PARÁMETROS QUÍMICOS Y MATEMÁTICOS}

\section{RESUMEN}

El impacto ambiental debe utilizar los indicadores de desarrollo de una nación no sólo los indicadores económicos como el PNB, ya cuenta con los datos disponibles en la literatura de otros índices, como el FNB y el IDH, lo que puede significar una mejor estimación del impacto ambiental del desarrollo. El IDH y el FNB miden el desarrollo de una nación, teniendo en cuenta otros factores que no son sólo económicos. El crecimiento demográfico y el desarrollo económico, están elevando las preocupaciones sobre la forma de garantizar formas más sostenibles de desarrollo humano (INTEGRATED MODELLING OF GLOBAL ENVIRONMENTAL CHANGE, 2006). El nitrógeno es un indicador de este impacto, por ejemplo en la forma de óxido de dinitrógeno (N2O) es altamente perjudicial para el medio ambiente debido a que causa la lluvia ácida y el agotamiento de la capa de ozono y contribuyen al calentamiento global, con 237 veces mayor impacto que el CO2. Los indicadores económicos se utilizan como referencia para estimar cómo el medio ambiente está siendo impactado (INTEGRATED MODELLING OF GLOBAL ENVIRONMENTAL CHANGE, 2006). EI concepto más amplio para medir el desarrollo de una sociedad es el índice de felicidad nacional bruta. En este trabajo se mide utilizando los No ecuaciones para el PIB y adaptado a la FNB, se dio cuenta de que las regiones más desarrolladas del mundo son los más grandes de nitrógeno de liberación a la atmósfera, mientras que las regiones más pobres son los datos menos significativo, consistente literatura usado.

PALABRAS CLAVE: Medio Ambiente. Índice de Desarrollo. Felicidade Interna Brutadice de felicidad total.

\section{INTRODUÇÃO}

A queima de combustíveis fósseis, a urbanização, o desmatamento, as queimadas e a agricultura, vêm acelerando o ciclo natural do nitrogênio, aumentando a sua fixação atmosférica. (INTEGRATED MODELLING OF GLOBAL ENVIRONMENTAL CHANGE, 2006). A fixação do nitrogênio $\left(\mathrm{N}_{2}\right)$ leva a formação 
de gases na forma oxidada e reduzida, como óxido nítrico (NO), óxido de dinitrogênio $\left(\mathrm{N}_{2} \mathrm{O}\right)$ e dióxido de carbono $\left(\mathrm{CO}_{2}\right)$. (CARVALHO; BUSTAMANTE, 2007).

Nitrogênio é um elemento químico essencial à vida, pois é constituinte das proteínas, do DNA e auxiliano crescimento de plantas. Além disso, compostos nitrogenados como óxido de dinitrogênio $\left(\mathrm{N}_{2} \mathrm{O}\right)$, óxido nítrico (NO), dióxido de nitrogênio $\left(\mathrm{NO}_{2}\right)$, ácido nítrico $\left(\mathrm{HNO}_{3}\right)$ e amônia $\left(\mathrm{NH}_{3}\right)$, estão relacionados com problemas ambientais como a chuva ácida, diminuição da camada de ozônio e poluição atmosférica. (MARTINS et al., 2003).

$\mathrm{O}$ óxido de dinitrogênio $\left(\mathrm{N}_{2} \mathrm{O}\right)$ tem seu potencial de aquecimento 237 vezes maior do que o do dióxido de carbono $\left(\mathrm{CO}_{2}\right)$, por molécula (HYPESCIENCE, 2010). Ou seja, o aumento da emissão desse gás é altamente nocivo aos seres humanos e, também, leva a destruição da camada de ozônio $\left(\mathrm{O}_{3}\right)$ que é responsável pela proteção contra as radiações ultravioleta.

$O$ presente trabalhoestuda a relação das emissões de nitrogênio com a Felicidade Interna Bruta (FIB) de diferentes regiões do mundo e compara com outros dois índices sociais o Produto Interno Bruto (PIB) e Índice de Desenvolvimento Humano (IDH).

Felicidade Interna Bruta (FIB)é um indicador de desenvolvimento social criado no Butão, país localizado no Sul da Ásia.(LUSTOSA; MELO, 2009).Ele baseia-se na ideia de que um país desenvolvido não é, apenas, aquele que possui a maior riqueza, mas sim, aquele em que a sua população é feliz.

$O$ índice FIB mede o desenvolvimento de um país utilizando nove parâmetros: bem-estar, saúde, tempo, vitalidade, educação, cultura, meio ambiente, governança e padrão de vida. (VIALLI, 2012).

\section{OBJETIVO}

O objetivo geral desta linha de pesquisa érelacionar desenvolvimento econômico e impacto ao meio ambiente. Neste trabalho o objetivo específico é calcular Nem utilizando o PIB, equação proposta por Van Drecht et.al.(2003), e comparar os valores obtidos com a Nem calculadas pelo FIB e IDH. 


\section{METODOLOGIA}

Foram utilizados dados da literaturaWorld Happiness Report (2013) para o PIB, IDH e FIB do ano de 2012 e 2013, para realizar a modelagem da emissão de nitrogênio em dez regiões mundiais, sendo elas: América do Norte, Europa Ocidental, América Latina e Caribe, Sudeste da Ásia, Europa Central e Oriental, Comunidade dos Estados Independentes, Leste da Ásia, Meio Leste e Norte da África, Sul da África e África Subsaariana. (HELLIWELL;RICHARD; SACHS, 2013).

Para realização do trabalho considerou-se dez regiões mundiais sugeridas pelo World Happiness Report (2013) e suas populações foram calculadas usando dados da literatura (Wikipedia, 2013). A seguir, apresentam-se as regiões e os países integrantes de cada uma:

- América do Norte, AmN: Canadá, Costa Rica, Groenlândia, Guatemala, México e Estados Unidos;

- Europa Ocidental, EuOc: Reino Unido, França, Irlanda, Suíça, Bélgica, Holanda e Luxemburgo;

- América Latina e Caribe, AmLaCa: Argentina, Bolívia, Brasil, Chile, Colômbia, Costa Rica, Cuba, Equador, El Salvador, Guiana Francesa, Guatemala, Haiti, Honduras, México, Nicarágua, Panamá, Paraguai, Peru, Uruguai e Venezuela;

- Sudeste da Ásia, SuAs: Tailândia, Filipinas, Malásia, Singapura, Indonésia, Brunei, Vietnã, Myanmar, Laos e Camboja;

- Europa Central e Oriental, EuCOr: Alemanha, Áustria Hungria, Polônia, Republica Checa, Eslováquia, Eslovênia, Croácia, Bielorrússia, Letônia, Lituânia, Rússia, Ucrânia, Moldávia e Romênia;

- Comunidade dos Estados Independentes, CEl:Armênia, Belarus, Cazaquistão, Federação Russa, Moldávia, Quirguistão, Tadjiquistão, Ucrânia, Uzbequistão, Azerbaijão e Turcomenistão;

- Leste da Ásia, LAs: China, Japão, Mongólia, Coréia do Norte, Coréia do Sul, Taiwan, Hong Kong e Macau; 
- Meio Leste e Norte da África. LNAf: Quênia, Somália, Etiópia, Uganda, Tanzânia, Marrocos, Tunísia, Argélia, Líbia e Egito;

- Sul da África, SuAf: África do Sul, Angola, Botswana, Burundi, República do Congo, Gabão, Guiné Equatorial, Lesoto, Madagascar, Malawi, Moçambique, Namíbia, Quênia, República Democrática do Congo, Ruanda, Suazilândia, Tanzânia, Uganda, Zâmbia e Zimbábue;

- África Subsaariana, AfSS:República Democrática do Congo, República do Congo, Burundi, África Oriental, Quênia, Tanzânia, Uganda, Djibouti, Eritréia, Etiópia, Somália, Sudão, África Ocidental, Benin, Burkina Faso, Camarões, Chade, Costa do Marfim, Guiné Equatorial, Gabão, Gâmbia, Gana, Guiné, Guiné Bissau, Libéria, Mauritânia, Mali, Níger, Nigéria, República CentroAfricana, Ruanda, Senegal, Serra Leoa, Togo e Zâmbia.

Na Tabela 1 é apresentado as populações de cada região.

Tabela 01: População por região.

\begin{tabular}{l|r}
\multicolumn{1}{c|}{ Regiões do mundo (2013) } & População \\
\hline Mundo & $7,20 \mathrm{E}+09$ \\
\hline América do Norte & $5,29 \mathrm{E}+08$ \\
\hline Europa Ocidental & $3,98 \mathrm{E}+08$ \\
\hline América Latina e Caribe & $5,96 \mathrm{E}+08$ \\
\hline Sudeste da Ásia & $4,00 \mathrm{E}+08$ \\
\hline Europa Central e Oriental & $3,91 \mathrm{E}+08$ \\
\hline Comunidade dos Estados Independentes & $2,74 \mathrm{E}+08$ \\
\hline Leste da Ásia & $1,58 \mathrm{E}+09$ \\
\hline Meio Leste e Norte da África & $3,59 \mathrm{E}+08$ \\
\hline Sul da África & $4,70 \mathrm{E}+04$ \\
\hline África Subsaariana & $5,00 \mathrm{E}+08$
\end{tabular}

Em trabalhos publicados pelo Painel Intergovernamental de Mudanças Climáticas (IPCC, Intergovernmental Panel on Climate Change), a emissão de nitrogênio, Nem, é baseada no Produto Interno Bruto (PIB).

A emissão de nitrogênio foi modelada em função do IDN e da FIB e comparado com os resultados do PIB. O PIB foi aplicado na equação sugerida por 
Van Drecht et.al.(2003), no livro Integrated Modelling of Global Environmental Change (IMAGE). A seguir apresenta-se a equação geral:

1. $N e m=8+11(P I B \div P I B \text { mundial })^{0.5}$

(eq. 01)

Onde:

- Nem: Emissões de nitrogênio em gramas per capita diárias;

- PIB: Produto interno bruto da região avaliada (PIB);

- O expoente desta equação relaciona PIB em função do padrão de consumo de alimentos.

Na modelagem de Nem em função dos indicadores PIB; IDH e FIB, a equação foi modificada gerando a equação 2 e 3 :
2. $N e m=8+11(P I B \div \text { maior } P I B)^{0.5}$
(eq. 02)
3. $N e m=8+11(I D H \div \text { maior } I D H)^{0.5}$
4. $N e m=8+11(F I B \div \text { maior } F I B)^{0.5}$

Os dados obtidos a partir destas equações foram transportados para o programa Origin $6.0^{\circledR}$. Foram testadas várias funções matemáticas e verificado qual tem o melhor ajuste e que tenha possibilidade de ser atribuído significados, físicos e químicos, para os seus parâmetros a matemáticos

\section{RESULTADOS E DISCUSSÕES}

Os resultados serão apresentado em três blocos: 4.1 Emissão de Nitrogênio e PIB; 4.2 Emissão de Nitrogênio e IDH; 4.3 Emissão de Nitrogênio e FIB e posteriormente eles serão comparados item 4.4.

\section{1- Emissão de Nitrogênio e IDH}


Abaixo apresentam-se os resultados obtidos para a modelagem realizada a partir da equação 02, utilizando os valores de PIB.

Tabela 2- Nem em função do PIB mundial e do maior PIB (AN) em diferentes regiões do mundo

\begin{tabular}{|lccc|}
\hline \multicolumn{1}{|c}{ Regiões do mundo (2013) } & $\begin{array}{c}\text { PIB x10 } \\
\text { US\$ }\end{array}$ & $\begin{array}{c}\text { Nem / (g/ hab dia) } \\
\text { PIB mundo }\end{array}$ & $\begin{array}{c}\text { Nem / (g/ hab dia) } \\
\text { Maior PIB }\end{array}$ \\
Mundo & 71,90 & & \\
América do Norte & 18,68 & 13,61 & 18,99 \\
Europa Ocidental & 7,62 & 11,58 & 15,02 \\
América Latina e Caribe & 5,08 & 10,62 & 13,74 \\
Sudeste da Ásia & 2,00 & 9,83 & 11,60 \\
Europa Central e Oriental & 7,16 & 11,47 & 14,80 \\
Comunidade dos Estados Independentes & 2,52 & 10,06 & 12,04 \\
Leste da Ásia & 16,20 & 13.22 & 18,24 \\
Meio Leste e Norte da África & 0,78 & 9,14 & 10,24 \\
Sul da África & 0,71 & 9,09 & 10,15 \\
África Subsaariana & 0,72 & 9,10 & 10,16 \\
\hline
\end{tabular}

Para melhor compreender os valores da Nem em função do PIB e determinar a função matemática a ela associada foi construído um gráfico e determinado a equação matemática a ele associado. 


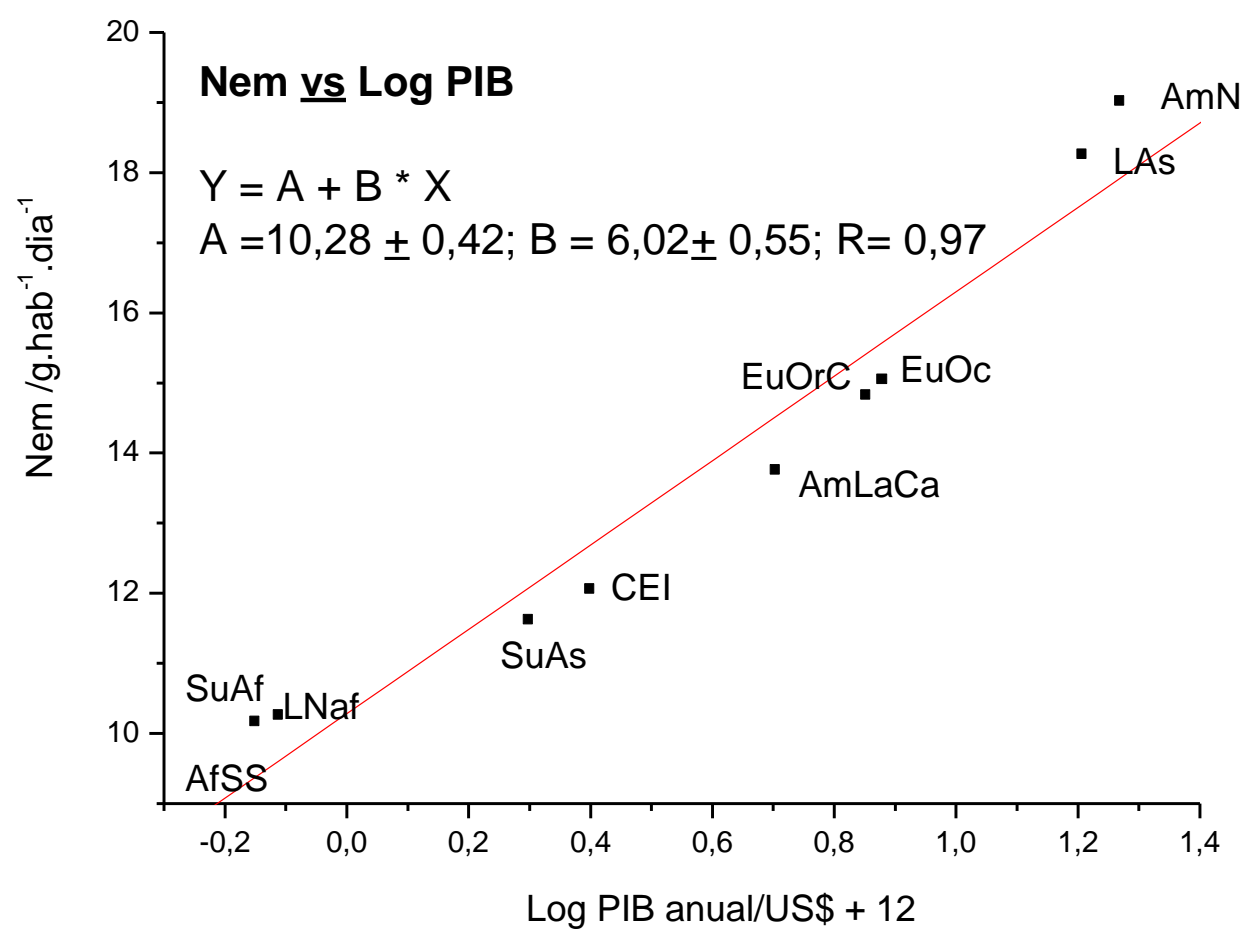

Figura 1- Nem em função do PIB relativo, (PIB/ PIB (AmN)).

A emissão de nitrogênio em função do PIB cresce seguindo uma função logarítmica

Sendo o eixo $x$, indicador econômico, um valor intrinsicamente associado a atividade humana, quando seu valor se aproxima de zero, $y_{0}$ a diferença entre o Nem máxima e o valor em $y_{0}$ indicará a contribuição que não é antropogênica, neste gráfico corresponde auma variação entre $(18,99$ - 10,28) 7,71 g/hab.dia e 10,15 $10,28)$ praticamente zero, pois não tem significado ambiental o valor negativo. a taxa de Nem cresce 6,02 g/hab.dia a cada aumento de um potência no valor do PIB.

\section{Emissão de Nitrogênio e IDH}

Abaixo apresentam-se os resultados obtidos para a modelagem realizada a partir da equação 03, utilizando os valores de IDH: 
$\mathrm{Na}$ Tabela 3 são mostrados os valores da $\mathrm{Nem}$ em função do IDH de diferentes regiões do mundo e na Figura 2 o gráfico associado a estes valores.

Tabela 03: Modelagem da emissão de nitrogênio utilizando IDH

\begin{tabular}{|lcc|}
\hline \multicolumn{1}{|c}{ Regiões do mundo (2013) } & IDH Nem (g/hab.dia) & \\
Mundo & 0,694 & 17,66 \\
América do Norte & 0,795 & 18,34 \\
Europa Ocidental & 0,899 & 19,00 \\
América Latina e Caribe & 0,721 & 17,85 \\
Sudeste da Ásia & 0,742 & 17,99 \\
Europa Central e Oriental & 0,814 & 18,47 \\
Comunidade dos Estados & 0,709 & 17,77 \\
Independentes & 0,827 & 18,55 \\
Leste da Ásia & 0,425 & 15,56 \\
Meio Leste e Norte da África & 0,478 & 16,02 \\
Sul da África & 0,566 & 16,73 \\
África Subsaariana & & \\
\hline
\end{tabular}

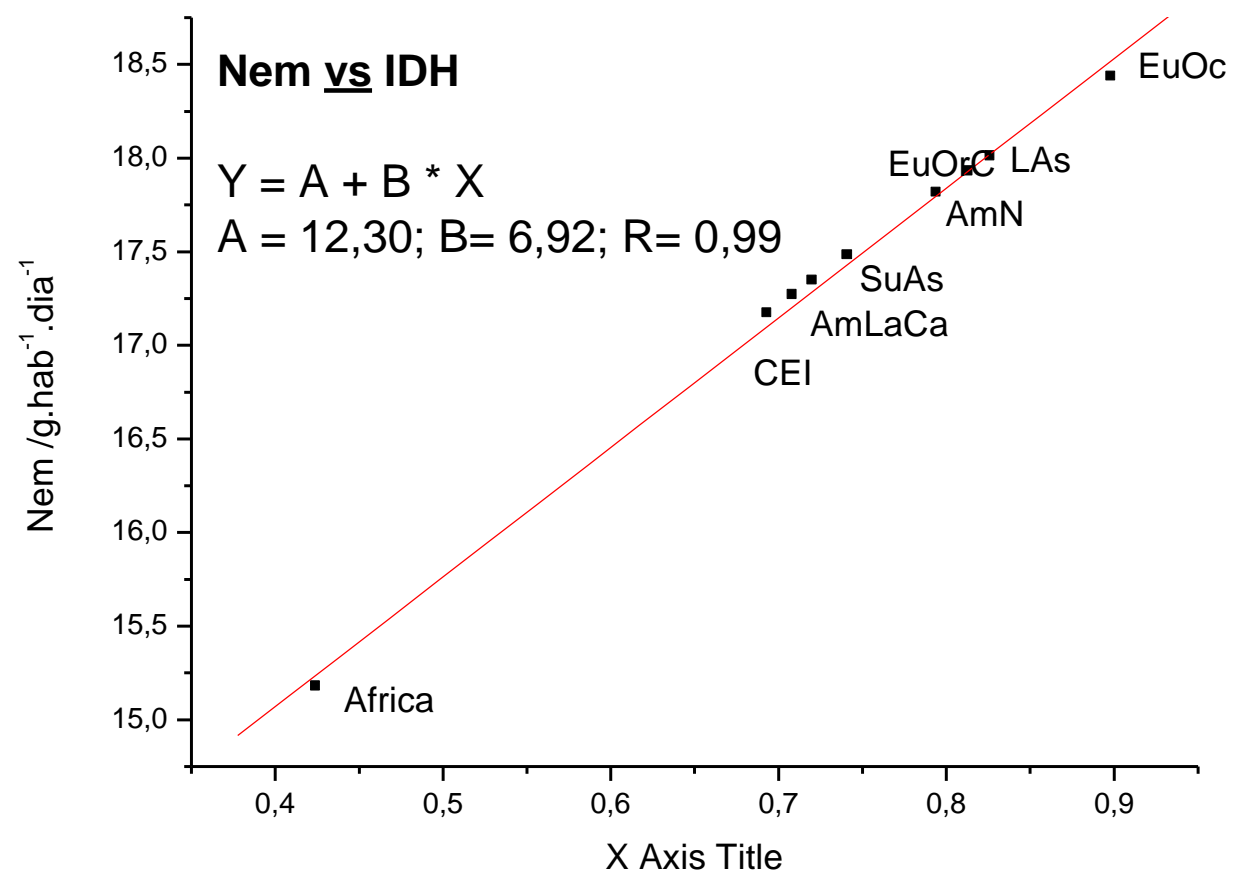

Figura 2- Nem em função do IDH, (IDH/maior IDH regional).

A partir dos dados apresentados acima pode-se verificar que a Nem cresce numa taxa de 6,92 g/hab.dia para cada unidade de IDH e quando o IDH apoxima-se 
de zero a Nem aproxima-se de um valor de 12,30 g/hab.dia e Nem devido a ação antropogênica.varia entre 6,70 e é 3,28 g/hab.dia.

\section{Emissão de Nitrogênio e FIB}

A Tabela 4 e a Figura 3 apresentam os resulados da modelagem matenáetica utilizando os valores da FIB para o cálculo da Nem.

Tabela 04: Modelagem da emissão de nitrogênio utilizando FIB

\begin{tabular}{|lrr|}
\hline \multicolumn{1}{|c}{ Regiões do mundo (2013) } & FIB & Nem (g/hab.dia) \\
Mundo & 5,158 & 17,36 \\
América do Norte & 7,133 & 19,00 \\
Europa Ocidental & 6,703 & 18,66 \\
América Latina e Caribe & 6,652 & 18,63 \\
Sudeste da Ásia & 5,43 & 17,60 \\
Europa Central e Oriental & 5,425 & 17,59 \\
Comunidade dos Estados & 5,403 & 17,57 \\
Independentes & 5,017 & 17,23 \\
Leste da Ásia & 4,841 & 17,06 \\
Meio Leste e Norte da África & 4,782 & 17,01 \\
Sul da África & 4,626 & 16,86 \\
África Subsaariana & & \\
\hline
\end{tabular}

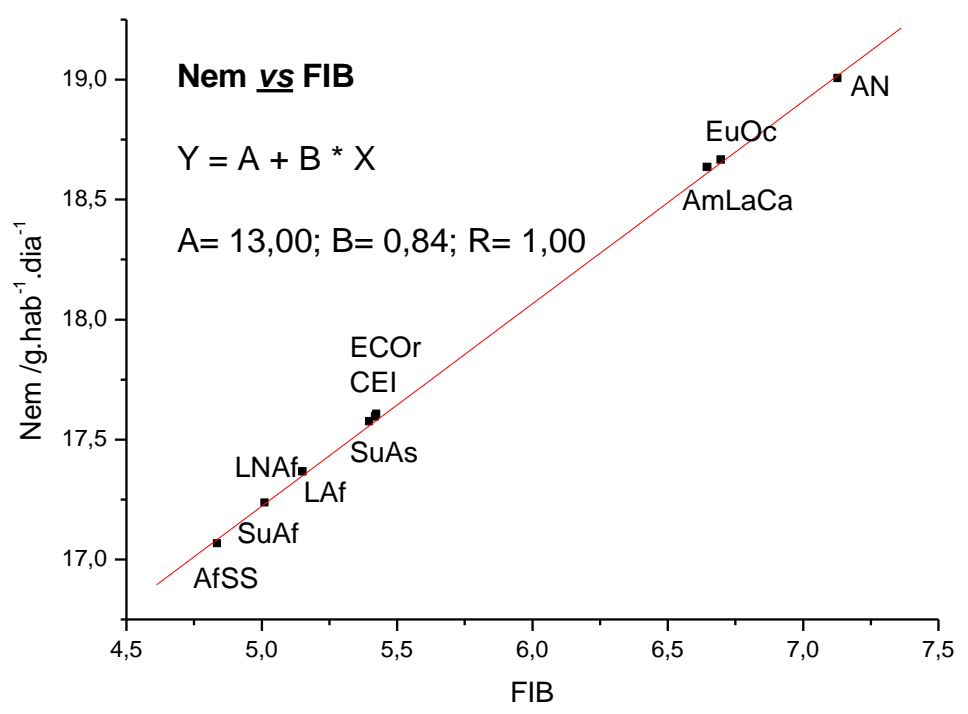

Figura 3- Nem em função do FIB, (FIB/maior FIB regional).

A partir dos dados apresentados acima pode-se verificar que a Nem cresce numa taxa de $0,84 \mathrm{~g} / \mathrm{hab}$.dia para cada unidade de FIB e quando o FIB se aproxima 
de zero a Nem aproxima-se devido a ação antropogênica varia entre 6,0 e 2,14g/hab.dia.

\section{4- Nem comparando PIB, IDH e FIB}

Os dados da Nem em função da FIB e do IDH são calculados utilizando os valores relativos a região que possui maior valor, IDH Europa Ocidental e FIB América do Norte, respectivamente, o PIB também foi calculado utilizando este mesmo fator de comparação, PIB da América do Norte, diferente da equação de Van Drecht et.al. (2003), que compara com o PIB mundial.

O PIB leva em conta a produção de riquezas de um determinado local, por isso, pode-se ver que, as regiões com os maiores valores de PIB compreendem as duas maiores economias mundiais: Estados Unidos e China, respectivamente.

Devido a sua extensão e por sua contribuição no PIB mundial, a América do Norte é quem mais libera nitrogênio na atmosfera, seguida do Leste da Ásia. Em contrapartida, as regiões africanas são as menos expressivas nos valores de emissão de nitrogênio.

Quando utilizamos o PIB mundial para calcular a Nem, equação de Van Drecht et.al.(2003) verificamos que os valores da Nem em função do PIB estão em concordância com os valores da literatura. Nela consta que, países desenvolvidos emitem de 15 a 18 gramas por pessoa por dia. Assim, a América do Norte, por concentrar países desenvolvidos e com alto nível de industrialização, obteve o maior valor de emissões de nitrogênio (13,61g por pessoa por dia), seguida pelo Leste da Ásia (13,22g por pessoa por dia).

Já as regiões africanas, consideradas subdesenvolvidas e muito pobres, apresentaram os menores valores de emissão de nitrogênio, estando estes concordantes com a literatura que diz que países menos desenvolvidos emitem, aproximadamente, 10 gramas por pessoa por dia.

Sendo assim, a menor emissão de todas é a do Sul da África $(9,09 \mathrm{~g}$ por pessoa por dia), seguida da África Subsaariana $(9,10 \mathrm{~g}$ por pessoa por dia) e do Meio 
Leste e Norte da África $(9,14 \mathrm{~g}$ por pessoa por dia). Essas regiões também apresentam os menores valores de IDH e FIB.

Estes dados mostram que o aumento nas emissões de nitrogênio é mais um fator que corrobora a premissa: quanto mais desenvolvido uma região maior o impacto ambiental que ele causa e nosso papel é conhecer melhor este impacto com o objetivo de mitiga-lo.

Por outro lado, calculando a Nem utilizando valor maior PIB, américa do norte, verifica-se que a velocidade de aumento na Nem, coeficiente angular das retas, os valores dos índices apresentam-se muito diferentes não sendo possível estabelecer um fator de comparação entre eles. Isto deve-se a sua metodologia de cálculos serem bem distintos, a informação mais útil, no momento, é seu valor absoluto, porém quando analisamos os valores da ação antropogênica, coeficiente linear, verificamos um concordância muito grande entre os valores, próximo de 11 g/hab,dia.

\section{CONCLUSÕES}

A modelagem da Nem utilizando o FIB mostrou uma correlação entre os dados calculados muito boa, e um comportamento semelhante ao IDH. Quando é comparado com o PIB é necessárias interpretações ambientais e sociais para se estabelecer uma correlação, porém é possível utilizar o FIB, um índice maia abrangente, para calcular a emissão nitrogênio.

A taxa de emissão de nitrogênio nos diferentes índices necessita de maior estudo para se estabelecer uma comparação. A ação antropogênica, coeficiente linear das retas estão próximso de $11 \mathrm{~g} / \mathrm{hab}$.dia mostrando uma concordância muito boa entre os diferentes índices.

As modelagens também mostraram que o desenvolvimento de uma região aumenta as emissões de nitrogênio, tendo como consequência alterações do seu ciclo natural causando desequilíbrios ambientais. O nitrogênio é um elemento essencial à vida e a produção de alimentos, porém, em excesso traz problemas à saúde e ao meio ambiente. 


\section{REFERÊNCIAS}

A economia. União Européia. 2014. Disponível em:<http://europa.eu/about-eu/factsfigures/economy/index_pt.htm>. Acesso em: 20 mai. 2015.

América Latina. Wikipedia. 2010. Disponível em:<http://pt.wikipedia.org/wiki/Am\%C3\%A9rica_Latina\#Pa.C3.ADses>. Acesso em: 12 mai. 2015.

Ásia Oriental. Wikipedia. 2010. Disponível em:<http://pt.wikipedia.org/wiki/\%C3\%81sia_Oriental>. Acesso em: 10 mai. 2015.

Associação de Nações do Sudeste Asiático. Wikipedia. 2014. Disponível em:<http://pt.wikipedia.org/wiki/Associa\%C3\%A7\%C3\%A3o_de_Na\%C3\%A7\%C3\%B5es_do_Su deste_Asi\%C3\%A1tico>. Acesso em: 10 mai. 2015.

BOBBINK, R; HORNUNG, M; ROELOFS, J.G.M. The effects o fair-borne nitrogen pollutants on species diversity in natural and semi-natural European vegetation. Journal of Ecology. Europa, v. 86, p. 717-738, 1998.

BOUWMAN, A.F. et al. Nitrogen Surfaces balances in Intensive Agricultural production systems in diferente world regions. Pedosphere, Potomac, v. 15, n. 2, p. 137-155, 2005.

Comunidade do Caribe. Caricom. 2014. Disponível em:<http://www.caerj.org.br/index.php?option=com_content\&view=article\&id=59\&ltemid=79>. Acesso em 10 mai. 2015.

CÓNSUL, J.M.D. et al. Decomposição catalítica de óxidos de nitrogênio. Química Nova, São Paulo, v. 27, n. 3, 2004. Disponível em: <http://www.scielo.br/scielo.php?pid=S010040422004000300013\&script=sci_arttext>. Acesso em: 07 abr. 2015.

Europa Ocidental. Wikipedia. São Paulo, 2015. Disponóvel em:<http://pt.wikipedia.org/wiki/Europa_Ocidental>. Acesso em: 10 mai. 2015.

FRANCISCO, W. de C. e. CEI. Mundo Educação. 2010.Disponível em:<http://www.mundoeducacao.com/geografia/cei-1.htm>. Acesso em: 10 mai. 2015.

GALLOWAY, J.N. et al. Nitrogen cycles: Past, presente, and future. Biogeochemistry, v. 70, p. 153-226, 2004.

HELLIWELL, J.; RICHARD, L.; SACHS, J. World Happiness Report 2013. New York. 2013. Disponível:<http://unsdsn.org/wpcontent/uploads/2014/02/WorldHappinessReport2013_online.pdf>. Acesso em: 01 mai. 2015.

INTEGRATED MODELING OF GLOBAL ENVIRONMENTAL CHANGE. Holanda: MNP, out. 2006.

Lista de países da América do Norte. Wikipedia. 2014. Disponível em:<http://pt.wikipedia.org/wiki/Lista_de_pa\%C3\%ADses_da_Am\%C3\%A9rica_do_Norte>. Acesso em: 11 mai. 2015.

Lista de Países por Índice de Desenvolvimento Humano. Wikipedia. 2013. Disponível em:<http://pt.wikipedia.org/wiki/Lista_de_pa\%C3\%ADses_por_\%C3\%8Dndice_de_Desenvolvime nto_Humano>. Acesso em: 10 mai. 2015.

Lista de Países por PIB nominal. Wikipedia. 2013. Disponível em:<http://pt.wikipedia.org/wiki/Lista_de_pa\%C3\%ADses_por_PIB_nominal>. Acesso em: 20 mai. 2015.

LUSTOSA, A. E.; MELO, L. F. de. Felicidade Interna Bruta (FIB): Índice de Desenvolvimento Sustentável. Goiás, 2009. Disponível em:<http://www.seplan.go.gov.br/sepin/pub/conj/conj14/artigo05.pdf>. Acesso em 01 mai. 2015. 
Nitrogênio é apontado como novo vilão do ecossistema. HYPESCIENCE. São Paulo, 2010.

Disponível em:< http://hypescience.com/nitrogenio-e-apontado-como-novo-vilao-doecossistema/>. Acesso em: 07 abr. 2015.

SOUZA, R. IDH 2012 - América Latina. Projeto Latino América. 2013. Disponível

em:<http://www.projetolatinoamerica.com.br/idh-2012-america-latina/>. Acesso em: 10 mai. 2015.

VAN DRECHT, G. et al. Global modeling of the fate of nitrogen from point and nonpoint sources in soils, groundwater and surfasse water. Global Biogeochemical Cycles., 2003. 